\title{
Liver damage associated with perhexiline maleate
}

\author{
D. LEWIS, H. C. WAINWRIGHT, M. C. KEW'1, S. ZWI, AND C. ISAACSON \\ From the School of Pathology of the South African Institute for Medical Research and the University of the \\ Witwatersrand, and the Department of Medicine, Johannesburg Hospital, and University of the \\ Witwatersrand, Johannesburg, South Africa
}

SUMMARY Two patients who developed biochemical and histological evidence of hepatitis while taking the anti-anginal drug perhexiline maleate are described. The pathological changes were those of mild to moderate fatty change together with a hepatitis which resembled alcoholic hepatitis, including in one patient the presence of material which by light microscopy was indistinguishable from Mallory's alcoholic hyalin. However, the predominantly periportal location of this material contrasted with the centrilobular distribution of Mallory's hyaline. One patient showed, in addition, severe atypia of the hepatocytes which was still present in less pronounced form 10 weeks after stopping perhexiline. The other patient had advanced hepatic fibrosis.

Various side-effects of the anti-anginal drug perhexiline maleate have been described, including hypoglycaemia (Feldman, 1974; Roger et al., 1975), neuromyopathy (Abaza et al., 1973; Lhermitte et al., 1976; Lageron et al., 1977), and abnormal liver function tests (Garson et al., 1973; Ikram et al., 1973; Pilcher et al., 1973; Martins de Oliveira et al., 1973; Howard and Rees, 1976; Lockhart and Masheter, 1976; Lageron et al., 1977). It was previously thought that changes in the liver enzymes were relatively mild and transient with little tendency to progress, and they were thus of little clinical significance (Newberne, 1973). The drug had been administered to several animal species for periods of 18 to 24 months, with doses of 16 times those used therapeutically, without any evidence of hepatic damage. More recently, however, isolated reports of abnormalities in liver biopsies from patients on prolonged perhexiline therapy have appeared (Beaugrand, 1976; Kopelman and Morgan, 1977; Lageron et al., 1977; McDonald, 1977).

This paper describes the liver biopsies of two patients in whom treatment of angina pectoris with perhexiline maleate was complicated by the development of raised serum enzymes and striking histological changes.

${ }^{1}$ Address for correspondence and reprint requests: Professor M. C. Kew, Department of Medicine, Witwatersrand University Medical School, Hospital Hill, Johannesburg 2001, South Africa.

Received for publication 14 September 1978

\section{Case 1}

Mr W.Q., a 63 year old retired goldminer, complained of a $18.1 \mathrm{~kg}(40 \mathrm{lb})$ weight loss, dizziness, weakness and numbness of his arms and legs, and a bitter taste in his mouth. The patient had suffered from angina pectoris for many years and had been receiving perhexiline maleate for three years initially in a dose of $200 \mathrm{mg}$ daily, but for nine months he had taken $400 \mathrm{mg}$ per day. Apart from the perhexiline, the patient was receiving no medication. There was no history of liver disease and he had taken no alcohol for 16 years. The patient was mildly hypertensive, but he was not in cardiac failure. He was obviously wasted and showed a global muscle weakness. Evidence of peripheral neuropathy was present. He was not jaundiced, but the liver was enlarged to $2 \mathrm{~cm}$ below the costal margin. There were no ascites, splenomegaly, or stigmata of chronic liver disease. An iron deficiency anaemia was also present, for which no cause could be found. The serum bilirubin and alkaline phosphatase concentrations were normal, but the serum glutamic oxaloacetic transaminase (SGOT) activity was $2180 \mathrm{mU} / \mathrm{m}^{2}$ and the glutamic pyruvic transaminase (SGPT) $2101 \mathrm{mU} / \mathrm{ml}^{2}$. After the first liver biopsy perhexiline was discontinued. This was followed by a gradual disappearance of his symptoms. The serum transaminase activity decreased progressively and returned to normal levels after three months. A second liver biopsy was performed three months after the initial biopsy and 10 weeks after stopping the perhexiline.

${ }^{2}$ Normal value $<35 \mathrm{mU} / \mathrm{ml}$. 
Microscopic examination of the initial liver biospy showed striking histological abnormalities (Fig. 1). The liver architecture was normal. Many of the hepatocytes exhibited gross enlargment due to marked cytoplasmic swelling. The nuclei were enlarged and exhibited marked variation in size with many binucleate hepatocytes, prominent hyperchromatism, and with nuclear atypia. The swollen hepatocytes exhibited equally florid cytoplasmic changes; many liver cells showed gross ballooning of their cytoplasm due to the presence of numerous small cytoplasmic vacuoles. Actual fatty change, however, was noted in only a minority of hepatocytes. Focal aggregates of polymorphonuclear leucocytes were present within the parenchyma, particularly in relation to swollen liver cells. Bile stasis was not noted. The portal tracts showed a mixed inflammatory infiltrate of neutrophils and mononuclear cells. There was no evidence of portal tract fibrosis.

The second liver biopsy showed considerable resolution of the parenchymal hepatitis and disappearance of the cytoplasmic vacuolation. Parenchymal changes were, however, still present (Fig. 2). Significant numbers of enlarged hepatocytes were noted, and nuclear atypia was still present, although it was far less marked than in the original biopsy. The portal tracts still exhibited a mild mono-
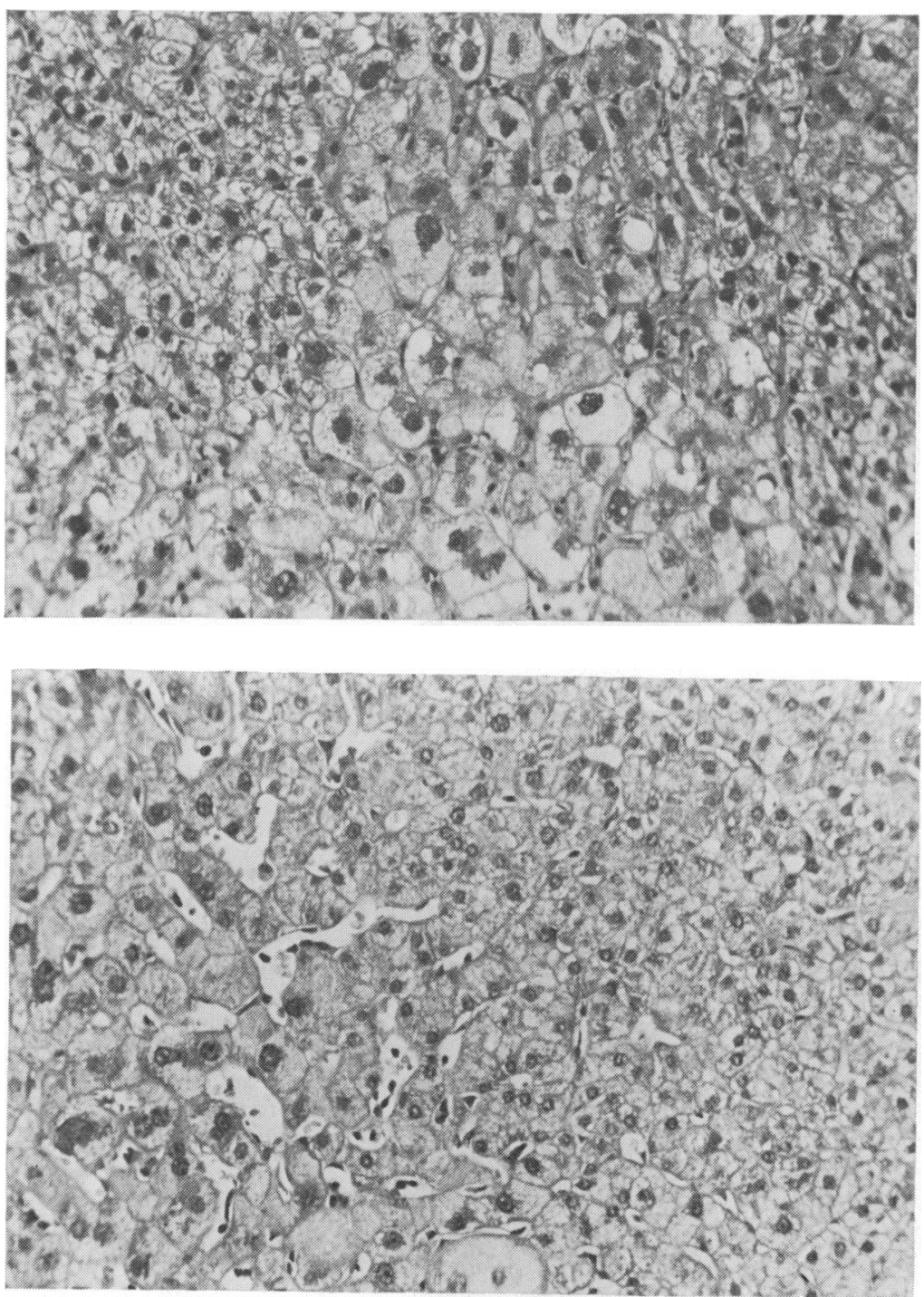

Fig. 1 Case 1. Section of initial liver biopsy showing marked atypia with considerable nuclear hyperchromatism and swelling of the cytoplasm. $H$ and $E, \times 360$ (original magnification).

Fig. 2 Case 1. Repeat biopsy 10 weeks after end of perhexiline maleate therapy. Some of the liver cells still show moderate atypia and swelling of the cytoplasm, but the changes are considerably less than in the original biopsy. $H$ and $E, \times 360$ (original magnification). 
nuclear cell inflammatory infiltrate but it was far less dense than originally observed.

\section{Case 2}

M.K., a 72 year old white male, complained of anorexia, generalised weakness, dizziness and blackouts, weight loss, and painful calves. He was known to suffer from gout, diabetes mellitus, and angina pectoris, and he had been receiving $200 \mathrm{mg}$ perhexiline daily for two years. The patient was taking allopurinol ( $300 \mathrm{mg}$ daily) for gout but his diabetes was treated with diet alone. There was no history of excessive alcohol intake. On examination he had a $4 \mathrm{~cm}$ enlargement of the liver but no jaundice, ascites, or splenomegaly. There were no stigmata of chronic liver disease and the patient was not in cardiac failure. The serum bilirubin was normal, SGOT $150 \mathrm{mU} / \mathrm{ml}$, SGPT $81 \mathrm{mU} / \mathrm{ml}$, alkaline phosphatase $111 \mathrm{IU}$, and gamma glutamyl transpeptidase $288 \mathrm{mU} / \mathrm{ml}$. A liver biopsy was performed. The patient subsequently developed bronchopneumonia and later died from septicaemia.

Microscopic examination of the liver biopsy showed marked distortion of the liver architecture, due to widening and fibrosis of the portal tracts, with extension of the fibrous bands into the hepatic parenchyma (Fig. 3). Considerable bile duct proliferation was noted and an inflammatory infiltrate of neutrophils was present in the portal tracts.
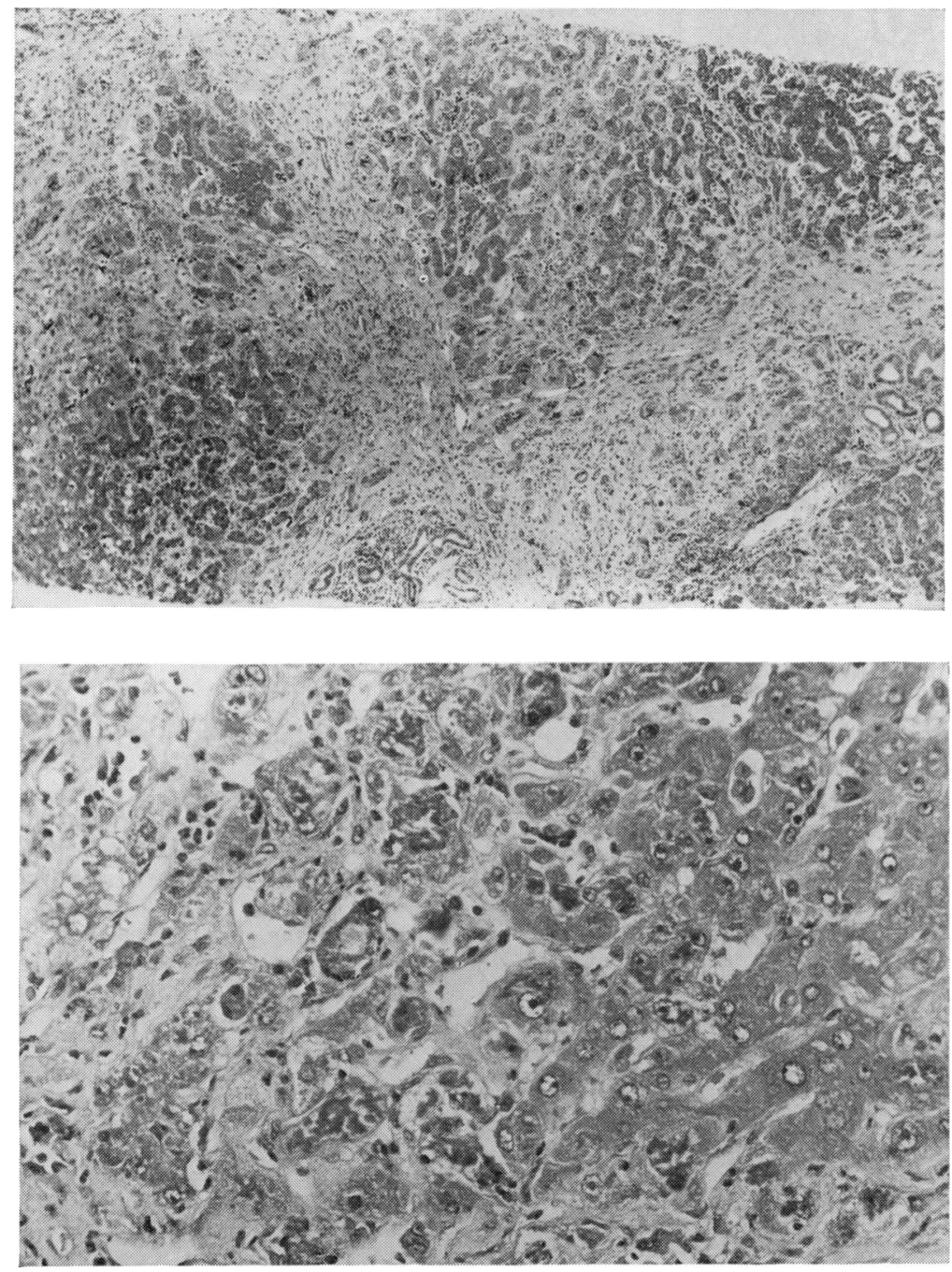

Fig. 3 Case 2. Liver biopsy showing markedly increased portal tract fibrosis with considerable swelling of the liver cells. Occasional necrotic liver cells are present. $H$ and $E, \times 90$ (original magnification).

Fig. 4 Case 2. Marked oedema of a portal tract (upper left). Some of the liver cells showing eosinophilic cytoplasmic clumping are surrounded by neutrophils. Other liver cells show large vesicular nuclei with prominent nucleoli. $H$ and $E, \times$ 360 (original magnification). 
Striking parenchymal abnormalities were evident. Although generalised, the changes were most severe in the periportal hepatocytes. The latter exhibited marked cytoplasmic swelling and fragmentation of their cytoplasm with the formation of clumps of intensely eosinophilic irregularly shaped strands (Fig. 4). These bore a superficial resemblance to Mallory's alcoholic hyalin, although the latter occurs in a predominantly centrilobular distribution. Many cells showing the eosinophilic clumping of the cytoplasm also demonstrated satellitosis by aggregates of neutrophils, the entire appearance being reminiscent of alcoholic hepatitis. Occasional isolated and degenerate liver cells were noted. Mild to moderate fatty change was present. Bile stasis was not observed and epithelial atypia was not noted, but significant numbers of hepatocytes showed the presence of large vesicular nuclei and prominent nucleoli, features suggesting active regeneration.

\section{Discussion}

A number of microscopic changes present in the liver biopsies from these two patients are similar to the findings described in the recent literature (Lageron et al., 1977; Kopelman and Morgan, 1977; McDonald, 1977). The picture is that of mild to moderate fatty change and a hepatitis which resembles alcoholic hepatitis, including the presence of material which by light microscopy looks similar to Mallory's alcoholic hyalin. Of note in both of our patients was the strong and reliable denial of alcohol intake, verified by several family members. It is very likely that these changes are drug induced, although it is not known whether the changes reflect a direct hepatotoxic effect of the drug or whether they are a result of hypersensitivity or idiosyncracy to the drug. The adverse effects of perhexiline may be potentiated by combination with oral anticoagulants (Kopelman and Morgan, 1977) or alcohol (McDonald, 1977). We are in agreement with those authors who regard the liver parenchymal changes as those of drug-induced hepatitis rather than representing a variation of type 1 glycogen storage disease, as has been proposed recently (Lageron et al., 1977). We would also agree that the 'florid' inflammatory component of the reaction appears to be reversible when the drug is withdrawn as was demonstrated in the follow-up in case 1 .

Although perhexiline has not been in general use for long enough to assess whether its prolonged use could result in more ominous changes, two features of these patients give cause for concern regarding the possible long-term deleterious effects of the drug. Firstly, the striking cellular atypia in case 1 , which persisted, although admittedly less pronounced, after the drug was stopped, must raise the question of possible permanent change and its further association with hepatic neoplasia. The presence of cellular atypia is known to be an important coexisting feature in association with cirrhosis and primary hepatocellular carcinoma (Anthony, 1973). Secondly, the presence of advanced fibrosis in case 2 should similarly be viewed with some concern, It is, however, possible that the portal tract fibrosis may have antedated the administration of the drug and additional cases will have to be studied in order to clarify this point.

\section{References}

Abaza, A., Cattan, D., Aziza, C., and Pappo, E. (1973). Effets secondaires mais réversibles à la prise de perhexilline. (Letter.) Nouvelle Presse Médicale, 2, 2820.

Anthony, P. P. (1973). Primary carcinoma of the liver-a study of 282 cases in Ugandan Africans. Journal of Pathology, 110, 37-48.

Beaugrand, M. (1976). Hépatite médicamenteuse à la perhexilline. (Letter.) Nouvelle Presse Médicale, 5, 1695.

Feldman, G. (1974). Hypoglycémie et perhexilline. (Letter.) Nouvelle Presse Médicale, 3, 2580.

Garson, W. P., Gülin, R. C., and Phear, D. N. (1973). Clinical experience with perhexiline maleate in forty-six patients with angina. Postgraduate Medical Journal, 49, April supplement, 90-92.

Howard, D. J., and Rees, J. R. (1976). Long-term perhexiline maleate and liver function. British Medical Journal, 1, 133.

Ikram, H., Chandrasekhar, K. P., Pilcher, J., Burns-Cox, C. J., Rees, J. R., Peirce, T. H., and Quinlan, C. D. M. (1973). Clinical evaluation of perhexiline maleate in patients with angina pectoris. Postgraduate Medical Journal, 49, April supplement, 94-95.

Kopelman, P., and Morgan, P. G. M. (1977). Liver damage after perhexiline maleate. (Letter.) Lancet, 1, 705.

Lageron, A., Poupon, R., de Saint Maur, P. P., and Lévy, V. G. (1977). Liver ganglioside storage after perhexiline maleate. (Letter.) Lancet, 1, 483.

Lhermitte, F., Fardeau, M., Chedru, F., and Mallecourt, J. (1976). Polyneuropathy after perhexiline maleate therapy. British Medical Journal, 1, 1256.

Lockhart, J. D. F., and Masheter, H. C. (1976). Perhexiline maleate in angina pectoris. (Letter.) British Medical Journal, 1, 1530-1531.

McDonald, G. S. A. (1977). Liver damage after perhexiline maleate. (Letter.) Lancet, 1, 1056.

Martins de Oliveira, J., Loyola, S. F., and Chaves, J. L. daC. (1973). Perhexiline maleate: eighteen months of continuous administration in patients with angina pectoris. Postgraduate Medical Journal, 49, April supplement, 78-86.

Newberne, J. W. (1973). Assessment of safety data from patients on short and long-term 'perhexilline therapy. Postgraduate Medical Journal, 49, April supplement, 125132.

Pilcher, J., Chandrasekhar, K. P., Rees, J. R., Boyce, M. J., Peirce, T. H., and Ikram, H. (1973). Long-term assessment of perhexiline maleate in angina pectoris. Postgraduate Medical Journal, 49, April supplement, 115-118.

Roger, P., Nogue, F., Ragnaud, J. M., Manciet, G., and Doumax, Y. (1975). Hypoglycémie après maléate de perhexilline. Nouvelle Presse Médicale, 4, 2663. 